\title{
INTRODUCCIÓN A LA CRIMINOLOGÍA
}

DaVID LORENZo MoRILLAS FERNÁNDEZ

Profesor Universidad de Granada, España

\section{Concepto y características}

Z 1 crimen es un hecho innato al ser humano. Por más que se retroceda en el 1 tiempo ambas variables se hallan presentes a lo largo de la historia. Desde el asesinato de Caín y Abel hasta nuestros días se han producido multitud de manifestaciones delictivas. El delito debe considerarse un hecho cíclico que aumenta o disminuye según los medios de control social adoptados por los diversos entes nacionales e internacionales. Durkheim lo definió como un fenómeno normal dentro de una sociedad, incluso aunque la misma estuviera compuesta por santos el crimen existiría ${ }^{1}$.

En teoría, la Criminología debiera ser una ciencia antiquísima en el tiempo pues al existir el crimen cohabitaría una disciplina encargada de su estudio. Bernaldo de Quirós señalaba al efecto que «criminología ha habido siempre, desde que ha habido crímenes (...); una Criminología, siquiera, incipiente, rudimentaria, elemental; tan elemental y tosca, tan pedestre y vulgar (...)»². Sin embargo, tal y como se concibe hoy -una ciencia empírica- su origen suele circunscribirse con la Escuela Positiva Italiana (Scuola Positiva) si bien es cierto que años antes de iniciarse esta corriente existían algunas pequeñas manifestaciones de estudios que dejaban vislumbrar una verdadera preocupación por el estudio serio y racional del hecho delictivo en su conjunto (frenología, fisionomía, psiquiatría, estadística moral...).

No existe un concepto unitario en torno a la definición de Criminología. La mayor parte de la doctrina aboga por asumir una serie de características comunes, propias e inherentes a la misma, independientemente del país de procedencia, a partir de las cuales comenzar a construir concepciones teóricas.

\footnotetext{
${ }^{1}$ Durkheim, E., Las reglas del método sociológico, Madrid, 1991, pp. 88-93.

${ }^{2}$ Bernaldo de Quirós, C., Criminología, Puebla, 1957, p. 8.
} 
A modo meramente de ejemplo, y a pesar de partir de modelos criminológicos totalmente opuestos no sólo en su fundamentación sino en su evolución -tal y como analizaré posteriormente-, el concepto de criminología no encuentra diferencias sustanciales en países tan dispares, en sus apariencias criminológicas, como Estados Unidos e Italia.

En el primero, Siegel define la Criminología como «aquella disciplina que emplea el método científico para estudiar la naturaleza, extensión, causas y control de la conducta criminal» ${ }^{3}$. Entre sus principales características, destaca la naturaleza interdisciplinar que abarca una gran variedad de campos tan variados como la sociología, el derecho penal, las ciencias políticas, psicología, economía y ciencias naturales ${ }^{4}$.

En Italia, Mantovani la identifica con «aquella ciencia multidisciplinar, interdisciplinar, sintética, centrada en un objeto de estudio realmente complejo como es el hecho de que "el hombre entre en conflicto con la sociedad", en todos sus aspectos: desde el proceso criminógeno hasta la definición de criminalidad, de sus causas a los medios de control social $»^{5}$. Al igual que sucedía con el concepto anterior, subraya como principales caracteres derivados de la definición expuesta, la pluridisciplinariedad, por la multiplicidad de competencias y conocimientos requeridos; e interdisciplinariedad, en atención a la necesidad de diálogo con otras disciplinas (biología, medicina, psicología, psiquiatría, psicoanálisis, sociología, antropología, pedagogía y ciencias económicas y jurídicas $)^{6}$.

En España, si hubiera que destacar alguna noción representativa del pensamiento mayoritario de la doctrina criminológica, esa sería sin lugar a dudas la de García-Pablos quien la concibe como «ciencia empírica e interdisciplinaria, que se ocupa del estudio del crimen, de la persona del infractor, la víctima y el control social del comportamiento delictivo, y trata de suministrar una información válida, contrastada, sobre la génesis, dinámica y variables principales del crimen -contemplado éste como problema individual y como problema social-, así como sobre los programas de prevención eficaz del mismo, las técnicas de intervención positiva en el hombre delincuente y los diversos modelos o sistemas de respuesta al delito»?

No obstante, como es lógico, enriqueciendo consecuentemente de contenido los postulados doctrinales, cohabitan una serie de conceptualizaciones muy próxi-

\footnotetext{
${ }^{3}$ Siegel, L., Criminology, Belmont, 2002, p. 3.

${ }^{4}$ Ibídem.

${ }^{5}$ Mantovani, F., Il problema della criminalità, Milán, 1984, p. 4.

${ }^{6}$ Ibídem.

${ }^{7}$ García-Pablos de Molina, A., Criminología: una introducción a sus fundamentos teóricos, Valencia, 2001, p. 33.
} 
mas a la expuesta aunque difieren puntualmente en algunos supuestos. A tal efecto, han de citarse las siguientes:

- Un sector doctrinal en el que cabe incluir a autores como Garrido, Stangeland y Redondo ${ }^{8}$; Hassemer y Muñoz Conde'; Jambu-Merlin, Stefani y Levasseur ${ }^{10}$; o Kaiser ${ }^{11}$ identifican la citada acepción como la ciencia que estudia la delincuencia y la reacción social frente a esos comportamientos.

- Herrero Herrero considera como concepto actual más aceptable el dado por Göppinger quien la uniforma con «aquella ciencia empírica e interdisciplinar que se ocupa de las circunstancias de la esfera humana y social relacionadas con el surgimiento, la comisión y la evitación del crimen, así como del tratamiento de los violadores de la Ley» ${ }^{12}$. La principal aportación llevada a cabo por este autor en atención a las demás concepciones presentadas es la inclusión, de forma expresa, del tratamiento como mecanismo de prevención de futuras conductas delictivas y reinserción social del individuo.

- Serrano Gómez restringe su ámbito de aplicación al delito y al delincuente al referirse a ella como «la ciencia que se ocupa del delito y del delincuente como fenómeno individual y social» ${ }^{13}$.

Mi percepción sobre el concepto de Criminología se halla muy próxima a los postulados indicados por García-Pablos, en tanto la Criminología debe ser definida como aquella ciencia empírica e interdisciplinar encargada del estudio del delito, del delincuente, de la víctima y de los medios de control social; que trata de suministrar una información válida y eficaz sobre el hecho delictivo, sus formas de actuación y prevención.

Conforme a ello pueden hacerse buenas las palabras de García-Pablos al identificarla como «una ciencia del "ser", "fáctica", "inductiva", en la que predomina la observación de la realidad sobre la perspectiva normativista y el método abstracto, formal y deductivo propio de otras ciencias» ${ }^{14}$. Sobre este último aspecto, Morillas Cueva destaca la naturaleza «cultural, empírico-social, valorativa y

\footnotetext{
${ }^{8}$ Garrido, Stangeland y Redondo la identifican con «la ciencia que estudia el comportamiento delictivo y la reacción social frente a tal comportamiento» (Garrido, V., Stangeland, P. y Redondo, S., Principios de Criminología, Valencia, 2001, p. 47).

${ }^{9}$ Hassemer y Muñoz Conde circunscriben el objeto de la criminología al «estudio (empírico) de la criminalidad, entendiendo por tal "el conjunto de todas las acciones u omisiones punibles dentro de un determinado ámbito temporal y espacial”» (Hassemer, W. y Muñoz Conde, F., Introducción a la Criminología, Valencia, 2001, pp. 24 y 25).

${ }^{10}$ Jambu-Merlin, Stefani y Levasseur indican que es «el estudio de las causas de la delincuencia» (Jambu-Merlin, R., Stefani, G. y Levasseur, G., Criminologie et Science pénitentiaire, París, 1985, pp. 2-3).

${ }^{11}$ Kaiser la relaciona con «el conjunto ordenado de saberes empíricos sobre el delito, el delincuente, el comportamiento socialmente negativo y sobre los controles de esta conducta» (Kaiser, G., Introducción a la Criminología, Madrid, 1988, p. 25).

${ }^{12}$ Herrero Herrero, C., Criminología, Madrid, 2001, p. 28. La definición original puede hallarse en Göppinger, H., Criminología, Madrid, 1975, p. 1.

${ }^{13}$ Serrano Gómez, A., Introducción a la ciencia del derecho penal, Madrid, 1981, p. 15.

${ }^{14}$ García-Pablos de Molina, A., Tratado de Criminología, Valencia, 1999, pp. 43 y 44.
} 
normativa en la Ciencia del Derecho penal; empírica y causal-explicativa en la Criminología» ${ }^{15}$.

En cuanto a las principales características de la Criminología, derivadas de la definición propuesta pueden reseñarse las siguientes:

1.1 Ciencia. Es uno de los aspectos que quizás pueda suscitar una mayor confusió $^{16}$. Como demostraré posteriormente, el método empleado por la Criminología es meramente científico; este hecho, no obstante, no permite otorgar de antemano el calificativo de ciencia pues bien pudiera hablarse de una disciplina basada en el método científico ${ }^{17}$.

Semejante calificativo ha sido empleado tradicionalmente para englobar diversos ámbitos tales como las Matemáticas, la Física, etc. sin embargo, hoy día, otros sectores del saber como el Derecho Penal han participado de esa denominación ${ }^{18}$. Así pues, ¿cómo es posible que conocimientos tan opuestos como la Física y el Derecho reúnan tal nomenclatura? La explicación a este fenómeno debe buscarse en las diversas distinciones o tipologías de ciencias obrantes a lo largo de la historia.

El punto de partida de esta cuestión hay que iniciarlo con la definición expuesta por el Diccionario de la Real Academia Española al contemplar, entre sus diversas acepciones, el vocablo "ciencia" en los siguientes términos:

a. Conjunto de conocimientos obtenidos mediante la observación y el razonamiento, sistemáticamente estructurados y de los que se deducen principios y leyes generales

b. Saber o erudición.

c. Habilidad, maestría, conjunto de conocimientos en cualquier cosa.

d. Conjunto de conocimientos relativos a las ciencias exactas, fisicoquímicas y naturales» ${ }^{19}$.

Por su propia naturaleza, las significaciones dos y cuatro quedan necesariamente excluidas en la posible identificación de la Criminología como ciencia en tanto no cumplimentan los requisitos establecidos al efecto; esto es, la acepción segunda hace expresa mención a una cualidad de la persona -saber o erudición, mientras el postulado cuarto engloba exclusivamente los conoci-

\footnotetext{
${ }^{15}$ Morillas Cueva, L., Metodología y Ciencia Penal, Granada, 1993, p. 316.

${ }^{16}$ Entre los autores que niegan el carácter de ciencia a la Criminología se hallan, entre otros, Rodríguez Manzanera, L., Criminología, México, 1982, pp. 11 y 12; Manheim, H., Comparative Criminology, Londres, 1965, pp. 19 y ss.

${ }^{17}$ Kaiser ya ponía de manifiesto esta dualidad, allá por la década de los ochenta, al afirmar que «domina hoy el acuerdo en que la Criminología es una Ciencia experimental y también, ampliamente, sobre que representa una disciplina autónoma. Sólo se pone en duda a veces la autonomía desde el lado psiquiátrico y sociológico. La pretensión de ser una ciencia empírica se refiere a los principios en que se apoya la investigación, fundada más sobre observaciones que sobre opiniones» (Kaiser, G., Introducción... cit., p. 28).

${ }^{18}$ Sobre la Ciencia del Derecho Penal vid. Morillas Cueva, L., Metodología... cit., pp. 11-40.

${ }^{19}$ Real Academia Española, Diccionario de la Lengua Española, 2001, versión electrónica (http://www.rae.es).
} 
mientos referentes a las ciencias exactas, fisicoquímicas y naturales a los que no cabe circunscribirla.

Ante ello, el posible debate en torno a su naturaleza se reduce a los apartados uno y tres de la referida noción. En atención a la primera de las acepciones expuestas y entre los criterios seguidos por la doctrina criminológica ${ }^{20}$ con el propósito de verificar si la Criminología verdaderamente es una ciencia, ha de traerse necesariamente a colación los postulados de Popper en este sentido, los cuales, en mi opinión, se han sobrevalorado ${ }^{21}$. Según este autor, un sistema científico consiste en un conjunto de hipótesis interrelacionadas que pueden someterse a contrastación a través de la observación de hechos ${ }^{22}$; es decir, se trata de repetir observaciones y experimentos para así controlar si los conocimientos adquiridos son realmente válidos y fiables ${ }^{23}$. De acuerdo con la naturaleza de la Criminología tal afirmación es apreciable en la práctica en tanto su método se fundamenta en tales parámetros. Sin embargo, más compleja resulta la matización expuesta al efecto sobre la deducción de principio y leyes universales, pues entre los principales argumentos defendidos entre los partidarios en negar la consideración de ciencia cabe reseñar la incapacidad para formular proposiciones universales y la falta de un método unitario y específico $^{24}$.

La primera de estas críticas, en una cuestionable opinión de García-Pablos, es salvable básicamente porque «comienza a admitirse que conocimiento científico no significa conocimiento exacto ni constatación de leyes universales, entendidas éstas en el sentido de las ciencias natura-

${ }^{20}$ Vid. Garrido, V., Stangeland, P. y Redondo, S., Principios... cit., pp. 52-57; Serrano Maíllo, A., Introducción a la Criminología, Madrid, 2003, pp. 30-40.

${ }^{21} \mathrm{Si}$, como este autor y otros siguiendo sus postulados ponen de manifiesto (vid. Popper, K. Conjeturas y refutaciones. El desarrollo del conocimiento científico, Barcelona, 1989, pp. 57 y ss; Garrido, V., Stangeland, P. y Redondo, S., Principios... cit., p. 53; Serrano Maíllo, A., Introducción... cit., pp. 30 y ss), un sistema científico consiste en un conjunto de hipótesis interrelacionadas contrastadas a través de la observación con el fin de verificar si tales hechos son válidos y fiables, el simple hecho de rellenar una quiniela de fútbol por un integrante de una peña creada para tal fin debe ser considerado como ciencia o sistema científico en tanto reúne los caracteres expuestos anteriormente pues la citada actividad contempla un conjunto de hipótesis (variables de la quiniela, antecedentes históricos, acumulación de jornadas...) y la observación de los partidos anteriores de los equipos integrantes de la misma con el objeto de establecer unos parámetros válidos y fiables que permitan predecir el signo quinielístico concreto con la intención de acertar los catorce resultados. Obviamente, la principal crítica efectuada a esta postura radica en la probabilidad de lograr un pleno de aciertos pues tal estudio no conforma unos postulados válidos y fiables en tanto existen factores externos no controlados por el peñista tales como las condiciones atmosféricas, la expulsión inicial de un jugador, lesiones de última hora (...) lo cual no permite garantizar la universalidad de dicho sistema. Semejante afirmación es comparable con la Criminología pues ambos estudios pueden predecir, en un tanto por ciento elevado las conductas desarrolladas por los sujetos, sin embargo el índice de probabilidad no es absoluto debido a variables no controlables por el sujeto ante lo cual cabe concluir que ninguna formula principios generales universales.

${ }^{22}$ Popper,, K., Conjeturas... cit., pp. 57 y ss.

${ }^{23}$ Garrido, V., Stangeland, P. y Redondo, S., Principios... cit., p. 53.

${ }^{24}$ García-Pablos de Molina, A., Tratado... cit., pp. 52 y 53. 
les» ${ }^{25}$. En atención a la segunda de las observaciones, como se expondrá a continuación, la Criminología goza de un método empírico e interdisciplinar; esto es, diversos conocimientos de otras tantas ciencias se conjugan a la vez con la finalidad de obtener una serie de datos propios explicativos de un fenómeno social. Este hecho la interrelaciona a las ciencias del ser como contraposición a las exactas. La explicación a esta proximitud radica en la multitud de funciones ostentadas -objeto de estudio en el siguiente epígrafe- pero, sobre todo, a la acumulación de datos que debe interpretar, sistematizar y valorar. Uno de sus objetos, consecuentemente, versa en observar un hecho delictivo concreto, extraer datos estadísticos sobre su volumen y analizarlos. En palabras de Schneider, el análisis empírico de los procesos de criminalización y descriminalización ${ }^{26}$. Con ello se obtendrán una serie de conclusiones mayoritarias y comunes a un porcentaje representativo de la población de delincuentes pero, en ningún caso, exactos; esto es, en definitiva, como señalan Hirschi y Stark, una relación de causalidad entre el fenómeno delictivo específico y un grupo mayoritario de victimarios ${ }^{27}$. Piénsese, como ejemplo, en la teoría del delito como elección racional o economicista $^{28}$ en virtud de la cual cuanto mayor sea el coste de la acción menos probabilidad de resolver el juicio de valor en favor de la conducta típica. Si esta teoría se cumpliera para la totalidad de los delincuentes, aquellos delitos castigados con la pena de muerte en diversos países no se cometerían bajo ningún concepto, sin embargo la realidad social es otra; o, por el contrario, se puede traer a colación el planteamiento expuesto por Suárez López en relación con el artículo 76 del Código Penal español ${ }^{29}$ en virtud del cual «quien ha cometido doce delitos contra la propiedad que merecerían cada uno la pena de un año de privación de libertad tendrá un máximo cumplimiento efectivo de tres años y la impunidad

${ }^{25}$ Ibídem, p. 54.

${ }^{26}$ Schneider,H., Kriminologie, Nueva York, 1987, pp. 84 y ss.

${ }^{27}$ Hirschi, T. y Stark, R., «Hellfire and delinquency», en Social Problems, 17, 1969, pp. 202-213.

${ }^{28}$ Entre los principales autores de esta teoría cabe citar a Wilson y Herrnstein (Wilson, J. y Herrnstein, R., Crime and Human Nature. The definitive study on the causes of crime, Nueva York, 1985) y Clarke y Cornish (Clarke, D. y Cornish, D., «Modeling Offenders' Decisions: A Framework for Research and Policy», en Tonry y Morris, Crime and Justice. An Annual Review of Research, vol. 6, Chicago, 1985, pp. 147-185) interpretan el crimen como el resultado de una elección racional; esto es, un hipotético juicio de valor entre los costes y beneficios de la acción delictiva, luego si el victimario delinque lo hará porque entiende que los beneficios que puede lograr gracias a esa conducta superan los costes. La solución que se plantearía por tanto consistiría en elevar la pena lo suficiente para que el juicio de valor se resolviera en favor de estos últimos evitando con ello el delito.

${ }^{29}$ Artículo 76 del Código Penal: «1. No obstante lo dispuesto en el artículo anterior, el máximo de cumplimiento efectivo de la condena del culpable no podrá exceder del triple del tiempo por el que se le imponga la más grave de las penas en que haya incurrido, declarando extinguidas las que procedan desde que las ya impuestas cubran dicho máximo, que no podrá exceder de veinte años (...)». 
de los nueve delitos sobrantes» ${ }^{30}$; es decir, el juicio de valor previo a la comisión del acto ilícito influirá en todos los victimarios a excepción de los que hayan cometido en concurso más de tres delitos.

En mi opinión, la Criminología no puede formular leyes ni principios generales universales ${ }^{31}$ por una razón muy sencilla y es que si esto fuera así se habría logrado determinar las claves para erradicar la delincuencia y, consecuentemente, viviríamos en una sociedad sin delito. A diferencia de las ciencias naturales, caracterizadas por presentar dos variables, una de entrada y otra de salida, que siempre se producirán -verbigracia, si se calienta agua destilada a 100 grados se evaporará, o tres más dos siempre suman cinco. La Criminología no contempla ambas constantes de manera global sino porcentual; esto es, incorporando tales resultados a la mayor parte de sujetos integrantes de la muestra pero existiendo siempre un mínimo contrario a los citados postulados, así el ya reseñado ejemplo de la aplicación de la pena de muerte en atención a la teoría del delito como elección racional. En consecuencia, no cabe dotar de contenido científico a la Criminología en virtud de la primera acepción referida en tanto no cumple con el requisito de enunciar principios y leyes generales, debiendo dotarla de tal significación gracias al postulado general tercero; es decir, la Criminología debe ser considerada como ciencia en tanto conforma un conjunto de conocimientos. Tal significación permite afirmar su carácter científico si bien es cierto que, en virtud de la misma, cualquier rama o campo del saber conformará una ciencia con tan sólo cumplimentar ese requisito básico.

En consonancia con este último planteamiento, un amplio sector doctrinal aboga por otorgar el carácter de ciencia a aquellos sectores de conocimiento que reúnan los siguientes caracteres: a) un conjunto de conocimientos que, para serlo, debe encarnar ciertas condiciones: fenómeno positivo, general, específico y capaz de ser sometido a análisis; b) presencia de un conjunto de elementos operacionales, a utilizar como propios de la ciencia que se trate; c) uso de método adecuado, obediente a reglas suficientemente definidas, de tal forma que sea capaz de conducir al conocimiento objetivo perseguido ${ }^{32}$.

En cualquier caso, de conformidad con las ideas expuestas hasta el momento, el término ciencia de la Criminología debe contemplarse como sinónimo de conjunto de conocimientos ${ }^{33}$.

${ }^{30}$ Suárez López, J. M., El concurso real de delitos, Madrid, 2001, p. 115.

${ }^{31}$ Semejante opinión es compartida por García-Pablos al afirmar que «la Criminología no es una ciencia exacta, capaz de explicar el fenómeno delictivo formulando leyes universales y relaciones de causa efecto» (GarcíaPablos de Molina, A., Criminología... cit., p. 130).

${ }^{32}$ Herrero Herrero C., Criminología... cit., p.31. En términos semejantes se muestra Rodríguez Manzanera al exigir la necesidad de uno o varios objetos, método y un cuerpo de conocimientos (Rodríguez Manzanera, L., Criminología... cit., p. 15).

${ }^{33}$ Kaiser comparte tal opinión al circunscribir la denominación "ciencia empírica" al «conjunto ordenado de saberes empíricos», términos estos últimos usados en su definición de Criminología (Kaiser, G., Introducción... cit., pp. 25 y 26 ). 
En cuanto a las diversas tipologías científicas y la subsiguiente configuración de la Criminología dentro de las mismas pueden traerse a colación, entre otras, las clasificaciones llevadas a cabo por Dilthey, quien distinguía entre ciencias naturales y del espíritu ${ }^{34}$; García-Pablos al hablar de ciencias exactas y del ser ${ }^{35}$; o Popper al diferenciar entre ciencias nomotéticas e idiográficas ${ }^{36}$. En cuanto a las primeras constituyen el verdadero núcleo de la ciencia pues, como señala Latorre, «las llamadas ciencias de la naturaleza, como la Física, la Química, la Biología, etc., en las que se veía no sólo el paradigma de unas ciencias exactas, cuyos resultados eran convincentes y universalmente válidos, sino también unos poderosos instrumentos para la investigación de la naturaleza, se encumbran como las verdaderas ciencias que sirven de modelo a todas las otras actividades intelectuales que pretenden recibir ese nombre ${ }^{37}$; las segundas, por su parte, manifiestan una adaptación de otros saberes distintos, en cuanto a su objeto, a aquéllas pues no contemplan un único resultado sino una generalidad común apreciable en la mayor parte de los sujetos integrantes de una muestra pero no a la totalidad.

Circunscribir la Criminología en alguna de las anteriores manifestaciones científicas es una cuestión ciertamente compleja. García-Pablos la incorpora, sin ningún género de dudas, a las ciencias de la naturaleza, invocando su carácter empírico ${ }^{38}$. Sin embargo tal afirmación no puede resolverse de una manera tan tajante pues cohabitan cuestiones a favor y en contra ${ }^{39}$. Por otra parte, si se la asocia a las ciencias normativas también se vislumbran disimilitudes entre ambas. Sobre este último hecho pueden traerse a colación las palabras de Sainz Cantero al distinguir entre Ciencia del Derecho Penal y Criminología en atención a «su naturaleza (normativa la Ciencia del Derecho Penal; empírica y causal-explicativa la Criminología), por su objeto de estudio (el aspecto normativo del delito la Ciencia del Derecho Penal; el aspecto real, la Criminología) y por el método que emplean (técnico-jurídico la primera; empírico, la segunda) $»^{40}$. En mi opinión, no cabe delimitar su pertenencia específica a alguno de los sectores científicos anteriormente reseñados pues sus propios caracteres la interrelacionan con ambas pudiendo hablarse de un híbrido próximo a las ciencias naturales y a las ideográficas

\footnotetext{
${ }^{34}$ Vid. García-Pablos de Molina, A., Tratado... cit., pp. 62-65, quien incluso considera obsoleta tal distinción.

${ }^{35}$ García-Pablos de Molina, A., Criminología... cit., p. 34.

${ }^{36}$ Popper, K., The Poverty of Historicism, Londres, 1976, pp. 121 y ss. Según este autor las ciencias nomotéticas tratan de descubrir y verificar leyes universales mientras las ideográficas se ocupan de la explicación causal de hechos individuales.

${ }^{37}$ Latorre, A., Introducción al Derecho, Barcelona, 1969, p. 111 y ss.

${ }^{38}$ García-Pablos de Molina, A., Tratado... cit., p. 63; y Göppinger, H., Criminología, Madrid, 1975, p. 9.

${ }^{39} \mathrm{~A}$ tal efecto puede volver a traerse a colación las variables de entrada y salida presentes en las ciencias naturales en virtud de las cuales, por ejemplo, la física puede determinar que la velocidad es igual al espacio partido por el tiempo frente a la Criminología, quien no puede detallar un principio o precepto universalmente válido.

${ }^{40}$ Sainz Cantero, J. A., Lecciones de Derecho Penal, vol. I, Barcelona, 1979, p. 85.
} 
-ambas en polos opuestos-. La mejor representación de esta dualidad de contenidos la manifiesta, en relación con la variedad de funciones ostentadas, García-Pablos al reseñar que «puede afirmarse que la Criminología es tanto una ciencia idiográfica como una ciencia nomotética. Una disciplina idiográfica que se preocupa de estudiar hechos, factores, probabilidades, etc., en relación con un caso individual. Pero, también, una disciplina nomotética que intenta descubrir leyes universales, correlaciones o tendencias constantes válidas desde un punto de vista científico, esto es, verificadas o no refutadas $»^{41}$. En definitiva, el carácter interdisciplinar y plurifuncional de la Criminología no permite contenerla conforme a una tipología científica en particular sino que, en mi opinión, debiera incluirse como un híbrido o en una posición intermedia entre las ciencias naturales y del espíritu, las exactas y del ser o las ideográficas y nomotéticas.

1.2 Método. De la definición expuesta de Criminología debe hacerse especial hincapié en su carácter de ciencia empírica e interdisciplinar.

a) Empírica. Kaiser la reduce «a un tipo de investigación, que está fundado más en la observación que en los argumentos u opiniones» ${ }^{42}$. Para GarcíaPablos éste es uno de los caracteres identificativos diferenciadores entre la Criminología y el Derecho Penal pues «mientras la primera se sirve de un método inductivo, empírico, basado en el análisis y la observación de la realidad, las disciplinas jurídicas utilizan un razonamiento lógico, abstractodeductivo» ${ }^{43}$.

Una de las funciones de la Criminología consiste en conocer la realidad y explicarla. Para ello necesita de estudios científicos a través de los cuales verificar una serie de hipótesis con el objeto de determinar si la conclusión a la que llega es fiable o no -y en todo caso aclarar la representatividad de la misma-, formulando teorías basadas en las citadas experiencias. En consecuencia, como afirma García-Pablos, «la Criminología no agota su cometido en la mera acumulación de "datos", sino que ha de transformar éstos en "información", en un núcleo de "conocimientos". Es decir, tiene que interpretar, valorar y sistematizar aquellos, integrándolos en una "teoría" o marco general de referencias ${ }^{44}$.

b) Interdisciplinariedad. Para comprender dicho carácter es necesario distinguirlo del concepto de multidisciplinariedad en tanto el primero hace referencia a un conjunto parcial de conocimientos de otra ciencia o disciplina de los que se basa la Criminología, el segundo agrupa a la totalidad de conocimientos conformadores

${ }^{41}$ García-Pablos de Molina, A., Tratado... cit., p. 65.

${ }^{42}$ Kaiser, G., Criminología, Madrid, 1983, p. 21.

${ }^{43}$ García-Pablos de Molina, A., Criminología... cit., pp. 36 y 37.

${ }^{44}$ García-Pablos de Molina, A., Tratado... cit., pp. 57 y 58. 
de esa ciencia o disciplina; esto es, el carácter interdisciplinar permite a la Criminología hacer suyas diversas nociones de otras ciencias de forma individual frente a la multidisciplinariedad que agruparía la totalidad de postulados ${ }^{45}$.

Jescheck y Weigend califican la Criminología como «una rama científica interdisciplinar» en tanto trabaja con datos fácticos sirviéndose de métodos de distintas ciencias naturales y sociales ${ }^{46}$. Siegel fundamenta esta aptitud en la diversidad de campos por los que se mueve pues necesita importar conocimientos de otras ramas del saber como la Sociología, el Derecho Penal, la Psicología, la Psiquiatría, las Ciencias Naturales, etc. ${ }^{47}$, conformando todas ellas una unidad de conocimientos propia. Sobre este aspecto Serrano Maíllo se muestra claro al afirmar que «muchas veces se ha confundido con que la Criminología fuera un mero batiburrillo inconexo de diversas disciplinas madre ${ }^{48}$ en clara alusión a esa remisión a otras ciencias para completar su contenido a través de diversas teorías, variables, conceptualizaciones (...) de otros sectores, lo cual no lleva a una dispersión de conocimientos sino a una unidad científica en donde, como manifiestan Serrano Gómez y Serrano Maíllo, «son relevantes enfoques y variables provenientes de disciplinas distintas $»^{49}$. La explicación de este fenómeno es sencilla pues radica básicamente, en que, como muy bien manifiesta García-Pablos, «el análisis científico del crimen, como comportamiento individual y como hecho social, requiere de una pluralidad coordinada de enfoques, ya que cada uno de ellos contribuye desde su particular óptica a un diagnóstico global, totalizador, del fenómeno delictivo (...) La Criminología es algo más que la Biología Criminal, que la Psicología Criminal o que la Sociología Criminal, pero tampoco puede prescindir de ellas» ${ }^{50}$. Mantovani, por su parte, conjuga ambos términos al especificar que «se trata de una disciplina autónoma, "pluridisciplinar" debido a la multiplicidad de competencias y conocimientos requeridos e "interdisciplinar" motivada por la necesidad de diálogo con diversas disciplinas (biología, medicina, psico-

\footnotetext{
${ }^{45}$ El carácter interdisciplinar no es secundado por la totalidad de la doctrina criminológica en tanto existen algunos autores, caso por ejemplo de Herrero Herrero (Herrero Herrero, C., Criminología... cit., pp. 201 y ss), que optan por atribuirle un contenido multidisciplinar lo cual, en mi opinión, no es del todo correcto pues a la Criminología no le interesan multitud de aspectos conformadores de otras ciencias recurriendo únicamente a aquellos que le sean útiles; o Serrano Má́llo, quien habla de ciencia autónoma aunque reconoce el carácter multidisciplinar como consecuencia de la unidad de la ciencia pues, en definitiva, todas las disciplinas lo son (Serrano Maíllo, A., Introducción... cit., pp. 45-48).

${ }^{46}$ Jescheck, H. y Weigend, T., Tratado de Derecho Penal, Traducción de Miguel Olmedo Cardenete, Granada, 2002, p. 50.

${ }^{47}$ Siegel, L., Criminology... cit., p. 3

${ }^{48}$ Serrano Maíllo, A., Introducción... cit., p. 47.

${ }^{49}$ Serrano Gómez, A. y Serrano Maíllo, A., «La paradoja del descubrimiento de la Criminología en España», en La ciencia del Derecho Penal ante el nuevo siglo, Libro Homenaje al Prof. Dr. D. José Cerezo Mir, Madrid, 2002, p. 1627.

${ }^{50}$ García-Pablos de Molina, A., Tratado... cit., p. 60.
} 
logía, psiquiatría, piscoanálisis, sociología, antropología cultural, pedagogía, ciencias económicas, ciencias jurídicas) $»^{51}$.

Conforme a estos postulados estimo necesario matizar la idea expuesta por Serrano Maíllo al identificar la Criminología como «una ciencia autónoma e independiente $\rangle^{52}$. No se trata, como emplea el citado autor parafraseando a Zafirovski, «de imponer al estudio del delito perspectivas propias de disciplinas concretas $\rangle^{53}$ sino que tales ramas del saber complementan y abren nuevas puertas a la Criminología; esto es, en este ámbito juega un papel trascendental la clásica distinción, ¿qué es y qué debiera ser la Criminología? En atención a esta última, la afirmación de Serrano Maíllo encuentra su lógica en países donde esta ciencia se ha consolidado como unidad de conocimiento gracias a la interdisciplinariedad de sus integrantes sin embargo los estados conformantes del llamado modelo europeo no ostentan tal especialización por lo que resulta bastante frecuente derivar conocimientos de otras disciplinas con el objetivo primordial de interpretar objetos derivados del delito, verbigracia, programas de tratamiento -situación actual de la Criminología en países como España, Italia, Portugal (...)-. El carácter de ciencia autónoma no creo que sea discutible pues su observancia es clara al efecto ${ }^{54}$ en tanto, bajo una perspectiva global, reúne aspectos delimitadores de la misma tales como objeto, método, teorías, etc. referentes a una unidad de conocimientos y ámbito de aplicación propios. Por el contrario, más complejo resulta, a mi entender, su identificación como ciencia independiente en tanto estimo que esta acepción choca frontalmente con su propio carácter interdisciplinar; esto es, ¿cómo concebir que una ciencia pueda ser independiente si necesita conocimientos de otras disciplinas para dotarla de contenido? Esta dualidad debe resolverse, en beneficio de la Criminología, en favor de la interdisciplinariedad en tanto permite unirla a otros saberes que avanzan a un ritmo de investigación mayor; negar la citada relación supondría eliminar pautas fundamentales de información e interpretación del hecho delictivo así como sus principales vías de prevención y actuación, implícitas en su propia definición. En consecuencia, la Criminología debe aspirar a eliminar ese carácter interdisciplinar en favor de su independencia, hecho que únicamente se producirá a partir del momento en el que comiencen a formarse verdaderos criminólogos dominantes de las principales ramas del saber englobadores de esta ciencia, no bastando un licenciado en Derecho o en Psicología con cono-

\footnotetext{
${ }^{51}$ Mantovani, F., Il problema... cit., p. 4.

${ }^{52}$ Serrano Maíllo, A., Introducción... cit., p. 45.

${ }_{53}$ Zafirovski, M., «The rational choice generalization of neoclassical economics reconsidered: any theoretical legitimation for economic imperialism?», en Sociological Theory, 18, 2000, p. 463.

${ }^{54}$ En semejante opinión vid., Morillas Cueva, L., Metodología... cit., pp. 309 y 317.
} 
cimientos básicos de otras ciencias quien constantemente debe remitirse a los conceptos de diversas disciplinas para abarcar su ámbito de actuación -esa es la interdisciplinariedad del conocimiento actual presente en España (el ser)-; sino que resulta necesaria la formación de auténticos expertos en Criminología dominadores de todos los saberes integrantes de esta ciencia para delimitar un campo de conocimiento propio en donde la remisión a las primeras cumpla una mera misión accesoria -entonces sí cabrá hablar de ciencia independiente (deber ser)-. Como ya he referido, el estado actual de la cuestión en el modelo europeo, responde a la primera premisa en tanto, como añade Raine, no se trata de una «destrucción del conocimiento» ${ }^{55}$ criminológico unitario en los términos expuestos por Serrano Maíllo sino un complemento pasajero necesario para el correcto funcionamiento y evolución de la Criminología, del carácter interdisciplinar hacia la independencia científica, camino ya superado en los países donde impera el modelo anglosajón.

En definitiva, puede concluirse como el método criminológico es eminentemente integral en tanto consiste en recabar datos y saber integrarlos e interpretarlos con la finalidad de dotar de una explicación coherente a un hecho ilícito, específico o general, sacralizando en muchas ocasiones el método estadístico. Con este propósito, la interdisciplinariedad jugará un papel esencial a la hora de dotar de contenido semejantes conclusiones pues permitirá a la Criminología completar un amplio catálogo de teorías generales sin las cuales su conocimiento quedaría anclado en el pasado mientras estas últimas no hallarían un referente, por sí mismas, a la hora de explicar el fenómeno delictivo.

1.3 Objeto. Tradicionalmente delincuente y delito fueron los objetos de estudio referentes para la Criminología tal y como puede observarse en las teorías criminológicas evolutivas -fisionomía, frenología, estadística moral (...)-. Sin embargo, a partir de 1950 la víctima del delito comienza a adquirir protagonismo en detrimento del primero pues, gracias a la información suministrada, pueden prevenirse futuros comportamientos delictivos. De igual forma, en torno a 1970, surgen los medios de control social como cuarto componente objeto de estudio debido, principalmente, a las teorías del labeling approach o social reaction approach.

Algunos autores, como es el caso de Kaiser o Jescheck y Weigend, ahondan en considerar a «los fenómenos del alcoholismo, de la asociabilidad, del causar molestias a la comunidad, de la prostitución y del suicidio» ${ }^{56}$ como

\footnotetext{
${ }^{55}$ Raine, A., The psychopathology of crime: criminal behaviour as a clinical disorder, San Diego, 1993, p. 309.

${ }^{56}$ Kaiser, G., Criminología. Una introducción a sus fundamentos cientificos, Madrid, 1983, p. 19; Jescheck, H. y Weigend, T., Tratado... cit., p. 50.
} 
objetos de la Criminología. En mi opinión, sin embargo, tales fenómenos no gozan de esa particularidad pues pueden ser subsumidos por alguno de los objetos reconocidos. Piénsese, por ejemplo, en la relación alcoholismo/criminalidad; inicialmente su consumo no lleva aparejado el desarrollo de ninguna actividad delictiva aunque bien es cierto que entre los efectos más comunes producidos durante su ingesta en grandes cantidades potencia, por sí misma o en combinación con otros factores, la probabilidad de desplegar una conducta violenta así como desinhibe los mecanismos del cerebro potenciando la agresión o bien mermando las facultades intelectivas del individuo ${ }^{57}$. Esto no quiere decir, ni mucho menos, que todo individuo consumidor de alcohol deba delinquir sino que su ingesta incrementa la probabilidad de cometer un hecho ilícito. Tal riesgo aumenta según la tipología delictual manifestada. A tal efecto, en el caso de la violencia doméstica, el alcohol juega un papel activo a la hora de manifestar la conducta típica como nexo o factor desencadenante de la misma luego la pregunta a formular debiera ser si el alcohol por sí mismo merecería ser un objeto propio de estudio por parte de la Criminología. Como ya referí anteriormente entiendo que no pues este elemento representa un posible factor desencadenante de la acción delictiva para una parte de los victimarios, intensa respecto a algunos delitos particulares pero nimia en cuanto a la población general, quedando subsumido por la figura del delincuente, el cual englobaría todos aquellos agentes externos incidentes en la personalidad del sujeto y en su futura conducta ${ }^{58}$. La misma subsunción acontecería con el resto de objetos propuestos por otros autores, como es el referido supuesto de Kaiser, en tanto los medios de control social, por ejemplo, comprenderían los supuestos referentes a la causación de molestias a la comunidad, la asociabilidad (...).

En definitiva, en mi opinión, el objeto de la Criminología se halla en la actualidad compuesta por cuatro ámbitos: delito, delincuente, víctima y medios de control social $^{59}$. Gráficamente, de manera muy acertada, Garrido, Stangeland y Redondo exponen las áreas de estudio de la Criminología de la siguiente manera ${ }^{60}$ :

\footnotetext{
${ }^{57}$ Sobre esta relación alcohol/violencia vid. Garrido, V., Stangeland, P. y Redondo, S., Principios... cit., pp. 513 y 514; Morillas Fernández, D. L., «Notas criminológicas sobre el consumo de drogas», en Morillas Cueva, Estudios jurídico-penales y político-criminales sobre tráfico de drogas y figuras afines, Madrid, 2003, pp. 415-417.

${ }^{58}$ Este tratamiento del alcohol en relación con el delito de violencia habitual en el ámbito doméstico puede contemplarse en Morillas Fernández, D. L., Análisis criminológico del delito de violencia doméstica, Cádiz, 2003, pp. 66 y ss.

${ }^{59}$ Semejante opinión es compartida por la mayor parte de la doctrina criminológica, pudiendo destacar a modo de ejemplo, entre otros, a García-Pablos de Molina, A., Criminología... cit., pp. 55 y ss; Garrido, V., Stangeland, P. y Redondo, S., Principios... cit., p. 49; Hassemer, W. y Muñoz Conde, F., Introducción... cit., pp. 24-33 (...).

${ }^{60}$ Garrido, V., Stangeland, P. y Redondeo, S., Principios... cit., p. 68.
} 


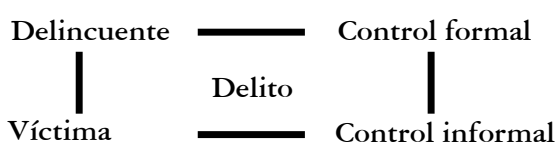

a) Delito. Contrariamente a lo que de inicio pudiera pensarse, la acepción delito no goza de la misma terminología en el campo criminológico como en el jurídico en tanto en la primera su ámbito de aplicación es más amplio. Semejante opinión es compartida por diversos autores entre los que cabe reseñar a Garrido, Stangeland y Redondo quienes circunscriben a la noción jurídica una perspectiva estética ya que analiza acciones específicas realizadas en un momento dado; frente a la criminológica, cuyo punto de partida radica en que un hecho delictivo aislado sólo puede ser adecuadamente comprendido si lo relacionamos con otros factores y comportamientos previos del mismo individuo, que no necesariamente tienen que ser delictivos ${ }^{61}$.

Desde una perspectiva normativa, delito, según el artículo 10 del Código Penal, es toda aquella acción u omisión dolosa o imprudente penada por la Ley. Consecuentemente, en virtud del principio de legalidad penal, para que una conducta sea considerada delito debe estar expresamente tipificada como tal en la Ley.

La Criminología, en mi opinión, va más allá pues no sólo contempla el delito en su acepción normativa sino también en su vertiente denominada crimen social; esto es, cualquier acción que, sin ser constitutiva de delito, genere un daño social, independientemente de su tipificación. Herrero Herrero justifica esta ampliación conceptual basándose en que si «la Criminología asumiera, sin más, este concepto de delito, se convertiría en pura y servilista servidora del Derecho Penal, dejando de lado cuestiones que ella sí debe tener claramente en consideración, como son los procesos de criminalización y descriminalización, con los que ha de enfrentarse con conciencia crítica» ${ }^{62}$. Es más, mantener una concepción unitaria de delito bajo la perspectiva jurídica llevaría implícito excluir diversas figuras relevantes desde el punto de vista criminológico como las autolesiones o el suicidio. A tal efecto, Muñoz Conde y Hassemer defienden una ampliación del objeto de la Criminología «a otras formas de "conducta desviada" (por ejemplo, prostitución, drogadicción), distintas a las declaradas legalmente como criminales, y a otras formas de reacción social distintas a las consecuencias jurídicas previstas para la comisión de un delito» ${ }^{63}$. Garrido, Stangeland y Redondo van más allá al destacar dos conjuntos de elementos no delictivos dirigidos «(a) hacia todas aquellas conductas infantiles y juveniles problemáticas o antisociales que pueden

${ }^{61}$ Ibídem, p. 50.

${ }^{62}$ Herrero Herrero, C., Criminología... cit., p. 143.

${ }^{63}$ Hassemer, W. y Muñoz Conde, F., Introducción... cit., p. 26. 
ser predictoras de la posterior delincuencia (entre ellas el absentismo escolar, la violencia infantil y juvenil, las fugas del hogar, etc.), y (b) hacia los diversos factores biopsicológicos y sociales facilitadores de la conducta delictiva» ${ }^{64}$. GarcíaPablos es claro al respecto al indicar que la Criminología «se ocupa de hechos irrelevantes para el Derecho Penal (vg. el llamado "campo previo" del crimen, la "esfera social" del infractor, la "cifra negra", conductas atípicas pero de singular interés criminológico como la prostitución o el alcoholismo, etc.); o de ciertas facetas y perspectivas del crimen que trascienden la competencia del penalista (vg. dimensión colectiva del crimen, aspectos supranacionales, etc. ${ }^{65}$. En consecuencia, mantener la equiparación en la noción de delito entre ambas ciencias llevaría implícito excluir, entre otras, a las denominadas conductas desviadas de la citada significación, privando a la Criminología de un campo de conocimiento fundamental para cumplimentar su función.

Ciertamente, la postura aquí defendida de extender el concepto criminológico de delito al crimen social es minoritaria en la doctrina criminológica si bien es cierto que la mayor parte de los autores, en algún momento de sus planteamientos, recurren a esta significación para definir, principalmente, la función crítica de esta ciencia. La disimilitud primordial entre ambas posturas radica en la asociación del término delito a «toda conducta definida, prohibida o punible bajo la ley penal» ${ }^{66}$. Como ya he reseñado a lo largo de este epígrafe, la Criminología debe estar ligada al Derecho Penal pero no por ello ha de abarcar únicamente ese ámbito; es más, una de sus funciones radica en mostrar estudios críticos a la legislación vigente con el propósito de adaptar las normas a la realidad social, lo cual lleva implícito medir cuantitativamente diversos comportamientos no tipificados como delito pero que, por su incidencia social, pueden merecer protección penal luego, consecuentemente con esta afirmación, el concepto de delito en Criminología debe abarcar más que en Derecho Penal. Por ello, y por otras razones que a continuación expondré, el crimen social debe estar presente en su ámbito de estudio ya que, de lo contrario, tal función carecerá de sentido -piénsese, por ejemplo, en el ya referido supuesto del suicidio-.

Serrano Maillo define delito, desde una perspectiva criminológica-jurídica como «toda infracción de normas sociales recogidas en las leyes penales que tienda a ser perseguida oficialmente en caso de ser descubierta ${ }^{67}$. La referencia expresa a "leyes penales" implica la naturaleza jurídica de la definición expuesta alejándose consecuentemente de la terminología “crimen social”. Pero es más, el propio au-

${ }^{64}$ Garrido, V., Stangeland, P. y Redondo, S., Principios... cit., p. 48.

${ }^{65}$ García-Pablos de Molina, A., Criminología... cit., pp. 58 y 59.

${ }^{66}$ Siegel, L., Criminology..., cit., p. 11.

${ }^{67}$ Serrano Maíllo, A., Introducción... cit., p. 65. 
tor circunscribe su conceptualización a aquellos supuestos en que sean perseguidos oficialmente ${ }^{68}$ en caso de ser descubiertos -aceptar esta tesis conlleva a su vez cerrar los ojos a la realidad social ${ }^{69}$ - y aborda la cuestión referente a los casos en que bien por la limitación de recursos bien por otras razones tales hechos no sean perseguidos, llegando a la conclusión de otorgar primacía a los delitos más graves en detrimento de los leves ${ }^{70}$. Esta consideración, a mi entender, pese a que en la práctica acontezca, no debe conformar el concepto de delito desde el plano criminológico en tanto su observancia eliminaría en consecuencia la mayor parte de conductas relacionadas con el crimen social restando importancia a tales hechos, los cuales si bien en una hipotética escala de valores convivirían en los niveles más bajos, no por ello deben eximirse de una especial protección a la víctima que los padece. Piénsese, por ejemplo, en el supuesto del comerciante que, con relativa frecuencia, encuentra en la pared de su establecimiento pequeñas pintadas de demonios lo cual reduce considerablemente la venta generándole un daño no sólo económico sino también la constante reparación de la infraestructura. Este hecho no sería inicialmente constitutivo de delito en términos jurídicos ni criminológico conforme a la definición expuesta por Serrano Mállo en tanto no representa un comportamiento delictivo y, en caso de serlo, como es un hecho ilícito menor, quedaría relegado a un segundo plano en favor de supuestos más graves.

La Criminología no debe cerrar las puertas a ninguna manifestación delincuencial contraria al orden social independientemente del resultado producido. Como afirman Hassemer y Muñoz Conde, «existen otras concepciones sobre lo que

\footnotetext{
${ }^{68}$ Basándose en los postulados de Cloward y Ohlin quienes exigen más bien que «cuando [el comportamiento sea] oficialmente conocido, evoque un juicio de los agentes de la justicia criminal de que tales normas [básicas de la sociedad] han sido violadas» (Serrano Maíllo, A., Introducción... cit., n.p.p. 218. La cita original se encuentra en Cloward, R. y Ohlin, L., Delinquency and opportunity. A theory of delinquent gangs, Nueva York, 1960, p. 3).

${ }^{69} \mathrm{El}$ caso de la violencia habitual en el ámbito doméstico es uno de los mejores ejemplos que pueden ayudar a comprender el riesgo que supone aceptar tal tesis. La violencia doméstica no es un fenómeno delincuencial descubierto en fechas recientes sino que ha estado presente a lo largo de la historia de manera encubierta. Hoy día, por ejemplo, se conoce la existencia de una gran cifra negra no sólo en lo referente al maltrato a mujeres, en el cual afortunadamente cada día se reduce el número de casos ocultos, sino, sobre todo, el producido a niños y ancianos. Obviamente si se recurre al método estadístico la proporción de sucesos en donde menores y personas mayores sean víctimas de violencia en el ámbito familiar otorgará unos resultados nimios. Sin embargo, hoy día se contempla la existencia de una gran cifra negra ocultadora del verdadero número de malos tratos a que son sometidos niños y ancianos en virtud de la cual se estima que tan sólo se conoce o denuncia en torno al $5 \%$ de los casos reales de maltrato. A tenor de la tesis sostenida por Serrano Maíllo, esta cifra negra no ostentaría la consideración de delito desde el plano criminológico en tanto se trata de supuestos desconocidos. Sin embargo, en mi opinión, ahí es donde la Criminología, entre otras funciones, debe hacerse valer para probar y denunciar la existencia de otra realidad social real.

Sobre esta cuestión de las cifras negras en materia de violencia habitual en el ámbito doméstico puede consultarse Morillas Fernández, D. L., Análisis... cit., capítulos referentes a la mujer -epígrafe exclusivo sobre las estadísticas, menor y anciano; o en referencia a este último Morillas Fernández, D. L., «Malos tratos a personas mayores: otra forma de violencia», en Actas de las Primeras Jornadas de Problemas Legales sobre Tutela, Asistencia y Protección a las Personas Mayores, Córdoba, 2001, pp. 205-210; o su versión electrónica en Revista Electrónica de Ciencia Penal y Criminología, núm 2, 2000 (http://criminet.ugr.es/recpc/recpc_02-r4.html).

${ }^{70}$ Serrano Maíllo, A., Introducción... cit., p. 66.
} 
debe ser o no ser delito, desde el punto de vista filosófico, moral o sociológico que no siempre coinciden con el concepto legal. La Criminología debe también ocuparse de estas concepciones, de las razones que la fundamentan y compararlas con la definición legal, sacando de ello las conclusiones que sean pertinentes para elaborar una Política criminal y proponer reformas legales, criminalizadoras o descriminalizadoras» ${ }^{71}$. Kaiser, de igual forma, manifiesta que «limitar el ámbito de investigación criminológica a las formas de aparición del concepto material del delito, partiendo de que pudiera determinarse con seguridad, no es razonable. La investigación empírica sólo resulta significativa jurídico-políticamente al objeto de obtener informaciones, para poder comparar y como orientación, cuando incluye en su horizonte toda la amplitud de las infracciones de las normas o de la conducta desviada. Según el problema que se plantee, es legítimo y necesario explorar, junto a las formas espectaculares de la delincuencia violenta o de la alta delincuencia, como secuestro de aviones, toma de rehenes y terrorismo, la de bagatela y los delitos de "caballeros", a como la "criminalidad cotidiana" $\gg$ ".

En consecuencia, mientras desde la perspectiva jurídica únicamente cabe hablar de un concepto de delito, desde la criminológica tal acepción contempla dos modalidades: el delito en sí y el crimen social. De este modo, ¿cuál es la relación práctica entre ambas variables? Entremezclando todas las posibilidades Rodríguez Manzanera contempla cuatro supuestos:

- Delito y crimen. Constituye la relación más frecuente entre ambas variables pues toda aquella conducta generadora de un ilícito penal causará necesariamente un daño social en tanto el primero se halla implícito en el segundo. Cualquier delito, por tanto, representará este supuesto, verbigracia asesinato, lesiones, robo (...).

- Delito sin crimen. Se produce cuando la acción no causa un daño social pero aparece tipificada como delito, por ejemplo la evasión de impuestos cuando el gobierno está corrompido y utiliza el dinero en beneficio personal de sus miembros siendo las víctimas los funcionarios que dejen de enriquecerse. Este es el único aspecto del que difiero con la opinión sostenida por este autor pues entiendo inapreciable en la práctica este supuesto por las razones expuestas en la relación anterior; esto es, el delito siempre lleva aparejado un daño social no cabiendo imputar como víctima, siguiendo el ejemplo anterior, al funcionario que deseche continuar atesorándose.

- Crimen sin delito. Cualquier acción que represente un daño social y no se halle tipificada como delito. Verbigracia el abuso de poder en tanto el victimario actúa dentro de la ley causando una serie de daños a una proporción de la población.

\footnotetext{
${ }^{71}$ Hassemer, W. y Muñoz Conde, Introducción ... cit., p. 28.

${ }^{72}$ Kaiser, G., Introducción... cit., p. 79.
} 
- Ni crimen ni delito. Conformaría el supuesto de aquella conducta no contraria al orden social en donde exista en términos generales una víctima. Por ejemplo, la amputación de una pierna llevada a cabo por un cirujano ${ }^{73}$.

En cualquier caso, la determinación de la concepción de delito a tener en consideración debe quedar fijada según los parámetros de la investigación que pretenda llevarse a cabo. Lo más común, debido al propio carácter de la Criminología, es utilizar la acepción normativa con el propósito de equiparar criterios. No obstante, suele asignarse, como regla general, a esta terminología un carácter básico o general mientras se recurre al crimen de manera accesoría.

b) El delincuente. Ha sido el objeto criminológico más estudiado en esta ciencia -a tal efecto conviene recordar como los antecedentes de la Criminología han girado siempre en torno al estudio de la persona del infractor- alcanzando su máximo protagonismo en la etapa positivista. Investigaciones como las llevadas a cabo por Della Porta ${ }^{74}$, aventajado representante de la fisionomía; Cubí y Soler ${ }^{75}$, con su teoría de la localización; $\operatorname{Lombroso}^{76} ; \operatorname{Kretschmer}^{77}, \operatorname{Sheldon}^{78}$, el matrimonio Glueck ${ }^{79}$ (...) representan excelentes ejemplos de esta corriente criminológica cuyo decaimiento comienza a observarse en torno al año 1920.

Hoy día, como nota predominante en los último años, la figura del victimario carece del protagonismo adquirido años atrás. Normalmente se suele hacer referencia a que es un objeto olvidado pero necesario pues complementa a los demás objetos de estudio - delito, víctima y medios de control social-. Sin embargo, desde mi punto de vista, estimo necesario el resurgimiento de esta figura en el ámbito de la Criminología pues aporta una información práctica demasiado interesante para despreciarla. A tal efecto, en atención al delito, cuestiones tan trascendentes como el modus operandi más frecuente empleado por el delincuente, sus hábitos (...); en torno a la víctima permitiendo dotar de una especial protección a aquellos sujetos conformadores de lo que se ha venido en denominar "víctimas especialmente vulnerables" 80 ; y sobre los medios de control social en tanto permite orientar de una forma eminentemente práctica los programas de política criminal; representan cuestiones de indudable interés investigatorio.

\footnotetext{
${ }_{73}^{73}$ Rodríguez Manzanera, L., Victimología, México, 1990, pp. 62 y 63.

${ }^{74}$ Della Porta, De humana physiognomia, Sorrent, 1586.

${ }^{75}$ Cubí y Soler, M., Manual de frenología, Barcelona, 1843.

${ }^{76}$ Lombroso, L'uomo delincuente, $1^{\mathrm{a}}$ Edición, Milán, 1876, con su tipología de delincuentes y su teoría de la criminalidad.

${ }^{77}$ Kretschmer, Köperbau und Charakter, Berlín, 1921, con su clasificación biotipológica de los victimarios.

${ }^{78}$ Sheldon, Varieties of Delincuent Youth, Harper, 1949; y su concepción embrionaria del delincuente.

${ }^{79}$ Glueck, S. y E., Physique and Delincuency, New York, 1956; con los factores que inciden en la criminalidad de las anteriores tipologías.

${ }^{80}$ Sobre el concepto de víctimas especialmente vulnerables, vid. Morillas Fernández, D. L., Análisis... cit., en prensa.
} 
En Estados Unidos desde hace un tiempo se ha redescubierto la figura del delincuente aumentando constantemente el número de investigaciones centradas en la persona del victimario. Creaciones de bases de datos tendentes a interrelacionar modus operandi y las técnicas de perfilación criminal representan algunos de los ámbitos de actuación en este sentido ${ }^{81}$.

En consecuencia entiendo que la investigación sobre el delincuente ha de recuperar parte del terreno perdido en el marco de la criminología. Una cosa es clara, si no hay delincuentes no hay delito, luego sabiendo como actúan y valorando preventivamente sus conductas, además de otorgar la protección normativa a las víctimas, aunque no se consiga erradicar el crimen -algo utópico, sí se logrará disminuirlo en cotas importantes.

c) La víctima. Representa, sin ningún género de dudas, el objeto olvidado por la Criminología, en tanto no será hasta 1950 cuando comience a hablarse de la importancia de esta figura en atención al hecho criminal. García-Pablos emplea la terminología «abandono de la víctima» para referir el escaso compromiso social existente con su figura, fundamentando tal postulado en que el Derecho Penal «se halla unilateral y sesgadamente volcado hacia la persona del infractor, relegando a la víctima a una posición marginal, al ámbito de la previsión social y del Derecho Civil sustantivo y procesal» ${ }^{82}$. Sin embargo, como ya he referido, a partir de mediados del siglo veinte comienza a adquirir un protagonismo esencial motivado principalmente por la información revelada sobre el crimen; esto es, la víctima, como parte de la denominada pareja penal, es capaz de suministrar una serie de datos tendentes a prevenir y actuar frente al delito. De manera explícita, Kaiser reseña que «la conducta de la víctima es relevante en múltiples sentidos. Se manifiesta tanto en las relaciones del delincuente, el hecho y el movimiento de la criminalidad, como también en las que se refieren al control del delito, la política jurídica y, finalmente, la investigación criminológica» $^{83}$. Su evolución en una hipotética escala cuantitativa de valor en el ámbito criminológico queda puesta de manifiesto, en primer lugar, por el reconocimiento de la pareja penal; el establecimiento de tipologías victimales ${ }^{84}$; el

\footnotetext{
${ }^{81}$ En materia concreta de asesinos en serie Estados Unidos se ha caracterizado por la creación del llamado VICAP, base de datos empleada por el FBI con la finalidad de interrelacionar asesinatos de unas mismas características permitiendo con ello trabajar a los investigadores con un abanico más amplio de información; o las técnica de perfilación criminal creadas sobre estos asesinos entre otros por Robert K. Ressler grcias a los múltiples estudios realizados a asesinos en serie. Sobre esta materia concreta puede consultarse Morillas Fernández, D. L., «Aspectos criminológicos de los psicópatas y asesinos en serie», en Cuadernos de Política Criminal, $\mathrm{n}^{\circ}$ 77, 2002, pp. 438-453.

${ }^{82}$ García-Pablos de Molina, A., Criminología... cit., pp. 69 y 70.

${ }^{83}$ Kaiser, G., Introducción... cit., p. 129.

${ }^{84}$ Los precursores en el establecimiento de tipologías victimales fueron Mendelsohn (Mendelsohn, B., «La Victimologie», Revue Francais de Psychenalise, janvier-fevrier, 1958, págs. 66 y ss) y Von Hentig (Hentig, H. The Criminal and his Victim, New Haven, USA, 1948; y El delito, Madrid, 1975, pág. 408 y ss).
} 
riesgo de victimización; los conceptos de victimización primaria y secundaria; la realización de estadísticas ${ }^{85}(\ldots)$.

En lo referente al concepto de víctima no cabe hablar de una noción unitaria en tanto cohabitan diversas posiciones alrededor del referido término cada una de ellas tendente a otorgar una protección concreta dependiendo de la rama, jurídica o social, que interese ${ }^{86}$. Entre las acepciones más empleadas por la doctrina victimológica caben reseñar las de la dogmática tradicional, quien equipara víctima al sujeto pasivo de la infracción que directamente sufre en su persona el menoscabo de sus derechos ${ }^{87}$; y, los autores que, bajo una perspectiva victimológica general, hablan de «aquella persona física o moral que sufre un daño producido por una conducta antisocial, propia o ajena, aunque no sea el detentador del derecho vulnerado» ${ }^{88}$.

Bustos Ramírez, por su parte, estima necesario diferenciar entre el concepto presentado por la Victimología y el del Derecho penal puesto que ambos son sustancialmente distintos. Así, frente a los conceptos penales, para la primera, víctima es cualquier afección sufrida por una persona en sus derechos, definición que escapa a la del Derecho penal ${ }^{89}$. Sin embargo, en la práctica criminológica lo más frecuente es equiparar el término víctima con el de sujeto pasivo del delito de conformidad con los postulados expuestos por la doctrina tradicional dogmática.

La reseñada expansión de la víctima lleva implícito el uso de la acepción Victimología para mencionar a la ciencia encargada de estudiar a la víctima. Si como se ha reseñado la Victimología conforma un saber propio, ¿cuál es la vinculación entre ésta y la Criminología? Para responder a esta cuestión, Rodríguez Manzanera opta por configurar tres grupos de interpretaciones llevados a cabo por diferentes autores tendentes a delimitar su naturaleza: ${ }^{90}$

\footnotetext{
${ }^{85}$ Entre las encuentas victimales más frecuentes debe hacerse especial hincapié en las encuestas de victimización. Se trata de cuestionarios estructurados en los que se realizan diversas preguntas a la víctima sobre un hecho delictivo concreto; verbigracia, las circunstancias en que se produjo el ilícito, relación con el agresor, tiempo y lugar (...). Suministra una información muy interesante sobre el fenómeno criminal y sus consecuencias bajo la perspectiva de la víctima. Como datos más significativos pueden evaluarse los índices de victimización, la eficacia de los programas de prevención, las características del hecho delictivo, el modus operandi más frecuente, la eficacia de los aparatos judiciales, acotar nuevas medidas de política-criminal para actuar y prevenir el crimen (...).

Muy próximas a éstas se hallan los Self-Report Surveys o autosondeos, los cuales consisten básicamente en preguntar de forma anónima a un porcentaje representativo de la población objeto de estudio cuestiones relacionadas con su participación o conocimiento de un hecho delictivo.

La diferencia entre ambas radica, principalmente, en que mientras en las primeras es necesario haber sido previamente víctima de un delito, en las segundas no es necesaria tal condición para llevarla a cabo.

${ }^{86}$ Una revisión conceptual sobre las diversas acepciones de víctima puede encontrase en Morillas Fernández, D. L., «Víctimas especialmente vulnerables en el delito de violencia doméstica», en Morillas Cueva, Estudios penales sobre violencia doméstica, Madrid, 2002, pp. 117-122.

${ }^{87}$ Vega Ruiz de, J. A., Las agresiones familiares en la violencia doméstica, Pamplona, 1999, p. 42.

${ }^{88}$ Rodríguez Manzanera, L., Victimología... cit., p. 66.

${ }^{89}$ Bustos Ramírez, J. y Larrauri Pijoan, E., Victimología: Presente y Futuro, Barcelona, 1993, pp. 17 y ss.

${ }^{90}$ Rodríguez Manzanera, L., Victimología... cit., pp. 14-21.
} 
- Autores que interpretan la Victimología dentro de la Criminología. Esta consideración apareja negar su autonomía científica. Entre los autores partidarios de este postulado cabe reseñar, entre otros, a Ellenberg, Goldstein, Göppinger, Gulotta, Neuman (...).

- Aquel sector doctrinal que circunscribe la Victimología como una ciencia autónoma con objeto, método y fin propios. Reconocer esta opinión dispone dotar de autonomía a esta ciencia respecto de la Criminología en tanto sería considerada una ciencia paralela ocupándose esta última únicamente de la figura del delincuente mientras la Victimología haría lo propio con la víctima. Entre sus defensores se hallan autores de la talla de Mendelsohn, Drapkin o Separovic.

- Negación de la Victimología. Este tercer grupo lo conformarían aquellos tratadistas que niegan no sólo la autonomía sino la existencia de la misma circunscribiéndola al saber propio de la Criminología. Entre sus principales representantes conviene reseñar a Jiménez de Asúa, López Rey, Kaiser (...).

En mi opinión, la Victimología debe ser entendida como una disciplina integrante de la Criminología. A tal efecto coincido plenamente con los postulados de Gulotta al señalar que «es una disciplina que tiene por objeto el estudio de la víctima, de su personalidad, de sus características biológicas, psicológicas, morales, sociales y culturales, de sus relaciones con el delincuente y del papel que ha asumido en la génesis del delito» ${ }^{91}$ en tanto que la misma encontrará una mayor comprensión, expansión y utilidad en el seno de la Criminología. Admitir otras tesis llevaría aparejado unos postulados ciertamente complejos pues reconocer la autonomía de la Victimología produciría una segmentación del fenómeno delictivo dificultando, aún más si cabe, las labores de investigación criminal, prevención y actuación contra el crimen; negar, por otro lado, su mera existencia, aún como disciplina, significaría cerrar los ojos a la realidad social y jurídica caracterizada precisamente por lo contrario; esto es, dotar de una mayor protección a la víctima mediante la creación de leyes, servicios sociales, nuevas figuras procesales, etc.

d) Los medios de control social. Su desarrollo como objeto de la Criminología se produce gracias, principalmente, al labeling approach o social reaction approach, teoría surgida en los años setenta intentando dar una explicación interaccionista del hecho delictivo o, lo que es lo mismo, aportar una disquisición científica a los procesos de criminalización. Según dicha teoría, no puede comprenderse el crimen prescindiendo de la propia realidad social, del proceso social de definición o selección de ciertas personas y conductas etiquetadas

${ }^{91}$ Gulotta, G., La vittima, Italia, 1976, p. 9. 
como criminales ${ }^{92}$. Delito y reacción son, por tanto, dos términos independientes pero inseparables.

El concepto de control social es ciertamente impreciso. A tal efecto, no existe una definición unitaria sobre el mismo sino que, pese a que la mayoría de los autores coinciden en la esencia, todos aportan ideas diferentes. Cohen lo circunscribe al conjunto «de formas organizadas en que la sociedad responde a comportamientos y personas que contempla como desviados, problemáticos, preocupantes, amenazantes, molestos o indeseables de una u otra manera (...) Esta respuesta aparece de diversas formas: castigo, disuasión, tratamiento, prevención, segregación, justicia, resocialización, reforma o defensa social. Está acompañada de muchas ideas y emociones: odio, venganza, desquite, disgusto, compasión, salvación, benevolencia o admiración. El comportamiento en cuestión es clasificado bajo diversas denominaciones: crimen, delincuencia, desviación, inmoralidad, perversidad, maldad, deficiencia o enfermedad. La gente a que se dirige esta respuesta es vista como monstruos, bobos, villanos, enfermos, rebeldes o víctimas. Y aquellos que responden (haciendo algo o estudiando la materia) -tareas que habitualmente se confunden- son conocidos como jueces, policías, asistentes sociales, psiquiatras, psicólogos, criminólogos o sociólogos de la desviación» ${ }^{93}$.

Para Wolf, el control social es el estudio de los «mecanismos a través de los cuales la sociedad despliega su supremacía sobre los individuos que la componen, consiguiendo que éstos acaten sus normas» ${ }^{94}$. En términos semejantes se muestra García-Pablos al hacer referencia a «ciertos procesos sociales que recaban la conformidad del individuo, sometiéndolo a las pautas, modelos y requerimientos del grupo; cohesión, disciplina, integración son, pues, términos que describen el objetivo final que persigue el grupo, la sociedad, para asegurar su continuidad frente al comportamiento individual irregular o desviado» ${ }^{95}$.

Por último, adelantando lo que va a tratarse como clases de medios de control social, se manifiesta Kaiser al tener que incorporar al objeto el análisis científico de los diversos sistemas normativos del control social (religión, moral, ética, usos y costumbres), de sus portadores e instancias (opinión pública, familia, escuela, profesión, etc.), estrategias (prevención, socialización, represión), de sus sanciones y destinatarios ${ }^{96}$.

\footnotetext{
${ }^{92}$ Entre los principales valuartes de esta teoría se hallan Garfinkel, H., «Conditions of Successful Degradation Ceremonies», en Symbolic Interacionism, Nueva York, 1972, pp. 201-208; Lemert (Lemert, E., Devianza, problemi sociali e formi di controllo, Milán, 1981); Matza (Matza, D., Delinquency and Drift, Nueva York, 1964); Conklin, quien ofrece una clara pespectiva del etiquetado (Conklin, J., Criminology, 1995, pp. 270 y ss.); (...).

${ }_{93}$ Cohen, S. «Visiones de control social», Traducido al castellano por E. Larrauri, 1988, pág. 15.

${ }^{94}$ Wolf, K.H. «Soziale Kontrolle», en Wörterbuch der Soziologie, editado por Bernsdorf, W., 1969, págs. 965-970.

${ }^{95}$ García-Pablos de Molina, A., Tratado... cit., p. 77.

${ }^{96}$ Kaiser, G., Introducción ... cit., págs. 111 y ss.
} 
Con esta aproximación al concepto de medios de control social, cabe centrarse en el análisis de las dos clases de medios que pueden observarse. De este modo, se distinguen entre medios de control social informales y medios de control social formales.

- Medios de control social informales. Garrido, Stangeland y Redondo los definen como el control «realizado por cualquier persona que actúa en un momento dado contra la delincuencia sin que el control del delito sea su actividad profesional» ${ }^{97}$. Operan a través de grupos primarios, como por ejemplo, la familia, vecinos, etc., o secundarios, tales como la escuela, puesto de trabajo, partido político (...).

- Medios de control social formales. Se ejercitan a través de instancias "ad boc" creadas para tal cometido. Verbigracia la policía, los tribunales de justicia, etc. Sus medios de actuación son muy variados pero siempre coercitivos.

La distinción entre ambos a veces resulta complicada ya que, normalmente, no actúan de forma independiente y tienden a solaparse. Lo que sí ha de tenerse claro es que el control formal está delimitado por la ley, que especifica las medidas a utilizar para aclarar un hecho delictivo, y las sanciones que se han de aplicar a los delincuentes. El control informal también está parcialmente acotado por ésta, en la medida en que determinados actos o conductas suelen estar prohibidos. Piénsese, por ejemplo, en los indultos o la auto justicia.

De igual forma, se puede afirmar que el control informal es mucho más activo y eficaz contra la delincuencia que el formal, siendo un excelente elemento de prevención de la misma. No obstante, como muy bien afirma García-Pablos, «los agentes de control social informal tratan de condicionar al miembro del grupo, de adaptarle a las normas sociales, de disciplinarle a través de un largo y sutil proceso que comienza en sus núcleos primarios (familia), pasa por la escuela, la profesión y la instancia laboral y culmina con la obtención de su actitud conformista, interiorizando el individuo las pautas y modelos de conducta transmitidos y aprendidos. Cuando las instancias informales de control social fracasan o el comportamiento desviado del individuo reviste una particular relevancia social o gravedad entran en funcionamiento las instancias formales (policía, proceso, etc.), que actúan de modo coercitivo e imponen sanciones cualitativamente distintas de las sanciones sociales: sanciones estigmatizantes que atribuyen al infractor un singular «status» (desviado, peligroso, delincuente, etc. $\rangle^{98}$.

${ }^{97}$ Garrido, V., Stangeland, P. y Redondo, S., Principios... cit., pág. 71.

${ }^{98}$ García-Pablos de Molina, A., Tratado... cit., p. 180. 


\section{Función de la criminología}

Una vez delimitado el concepto de Criminología y todos sus caracteres integrantes conviene a continuación detenerse a configurar cuáles son las funciones primordiales a cumplimentar. Sobre este aspecto García Pablos señala como ministerio principal «informar a la sociedad y a los poderes públicos sobre el delito, el delincuente, la víctima y el control social, aportando un núcleo de conocimientos más seguro y contrastado que permita comprender científicamente el problema criminal, prevenirlo e intervenir con eficacia y de modo positivo en el hombre delincuente» ${ }^{99}$. De manera más particular coincido plenamente con el planteamiento desarrollado por Serrano Maíllo ${ }^{100}$ destacando cuatro cometidos específicos:

a) El estudio de las causas del delito. Una de las misiones primordiales de la Criminología debe ser necesariamente explicar el proceso delictivo, tanto desde una perspectiva general como particular -lo cual lleva implícito en su propia génesis el estudio del delito, del delincuente, de la víctima y de los medios de control social-. Con tal fin se han elaborado una serie de teorías tendentes a buscar un hilo conductor que relacione la conducta humana con el fenómeno criminal. Teorías como la de las subculturas criminales de Cohen ${ }^{101}$, el delito como elección racional de Becker ${ }^{102}$; Wilson y Herrnstein ${ }^{103}$; o el perfeccionamiento de la misma llevada a cabo por Clarke y Cornish ${ }^{104}$; la oportunidad o las actividades rutinarias de Cohen y Felson ${ }^{105}$, la anomia de Durkheim ${ }^{106}$; o el aprendizaje social de Sutherland ${ }^{107}$ representan algunos ejemplos de semejante iniciativa.

b) Prevención y control del crimen. El estudio de las causas originarias de la acción criminal reporta otras consecuencias accesorias como bien pudiera ser una importante fuente de información sobre la génesis del delito. Conocido este aspecto resultará menos gravosa la adopción de medidas concretas tendentes a prevenir y actuar frente al crimen. En la práctica es uno de los grandes déficits presentados por las legislaciones internacionales en el sentido de crear una serie de normas o medidas de control social -formales e

\footnotetext{
${ }_{99}$ García-Pablos de Molina, A., Criminología ... cit., p. 130.

${ }^{100}$ Serrano Maíllo, A., Introducción ... cit., pp. 23-27.

${ }^{101}$ Cohen, A., Delinquent Boys. The Culture of the Gang, 1955, Illinois.

${ }^{102}$ Becker, G., «Crime and Punishment: An Economic Approach», en Journal of Political Economy, 76, 1968, pp. 169-217.

${ }^{103}$ Wilson, J. y Herrnstein, R., Crime... cit.

${ }^{104}$ Clarke, R. y Cornish, D., «Modelling...» cit., pp. 1 y 2.

${ }^{105}$ Cohen, A. y Felson, M., «Social change and crime rate trends: a routine activity approach», en Annual Review of Sociology, 44, 1979, pp. 589 y ss.

${ }^{106}$ Durkheim, E., El suicidio. Estudio de Sociología, Madrid, 1928, pp. 257 y ss.

${ }^{107}$ Sutherland, E., «White Collar Criminality», en American Sociological Review, 5, 1940, pp. 2-10.
} 
informales- basadas en un desconocimiento de la praxis criminal; esto es, la ausencia de estudios criminológicos, sobre todo en aquellos países donde impera el modelo criminológico europeo, lleva implícito que se legisle bajo una creencia que puede o no ser cierta pero sobre la que no existen estudios empíricos que respalden la adopción de tales medidas. Sainz Cantero señala al efecto que «cualquier proposición de lege ferenda realizada en la fase crítica de la metodología punitiva que no reciba esas conclusiones, corre el riesgo de resultar aventurada y falta de base ${ }^{108}$. Obviamente en una sociedad donde imperen semejantes investigaciones las normas se adecuarán a las necesidades sociales sobre seguridad ciudadana, proponiendo campos de actuación y, consecuentemente, una política-criminal efectiva sobre el hecho delictivo tanto en su vertiente particular como general.

c) Medición del fenómeno delictivo. Ya ha sido puesto de relieve a lo largo de este trabajo la importancia del método estadístico para la Criminología aludiendo incluso a una posible sacralización del mismo. Sin embargo, esta actividad cuantitativa permite verificar la correcta actuación en diversos frentes orientados a la prevención y lucha contra la criminalidad. Del mismo modo, delimitada una cifra media cíclica y constante de un delito concreto, de conformidad con los postulados de la Estadística Moral ${ }^{109}$, puede observarse su frecuencia media relativa y determinar diversas cuestiones tales como los delitos más comunes, la necesidad de adoptar políticas específicas para un determinado ilícito cuando se supere esa cifra media a la que acabo de hacer mención, distribuir geográficamente las zonas de predominio de una tipología delincuencial, verificar si los medios de control social acotados han sido efectivos (...).

Este cálculo, no obstante, debe ser practicado con suma cautela respetando siempre los principios estadísticos obrantes al efecto. No todo estudio delictual lleva aparejado la veracidad de sus resultados. Es más, en la práctica resulta bastante común encontrar mediciones practicadas sobre un mismo hecho delictivo que sorprendentemente arrojan cifras diferentes. Esta dismilitud se debe normalmente bien a que el campo objeto de estudio difiere en algún elemento -piénsese a tal efecto en el supuesto de dos muestras que pretenden medir el número de mujeres muertas víctimas de violencia habitiual en el ámbito doméstico durante el año 2003, registrando el primero 43 por 61 el segundo; con semejantes resultados una de ellas debe haberse falseado, sin embargo si se observa detenidamente la población objeto de estudio puede

${ }^{108}$ Sainz Cantero, J. A., Lecciones... cit., p. 87.

${ }^{109}$ Según esta escuela, el crimen es una magnitud regular y constante que se repite periódicamente fruto de las leyes sociales y regidas por leyes naturales. 
comprobarse como aquél incluía únicamente a mujeres casadas en el momento de producirse el fatal desenlace mientras éste agrupaba cualquier relación de pareja independientemente de la existencia de vínculo matrimonial (separaciones, divorcios, parejas de hecho, matrimonio...)- o bien ha sido sesgado. En cualquier caso, en mi opinión, primando un criterio legal de procedencia suelo distinguir entre fuentes oficiales y no oficiales ${ }^{110}$.

\section{d) Crítica a los medios de control social formales e informales a través} de los estudios realizados. Esta función presenta multitud de divergencias pues, como señalan Muñoz Conde y Hassemer, «la relación entre el saber normativo y el empírico propio de cada una de estas formas de abordar la misma realidad, no es, sin embargo, idílica, sino conflictiva, y tiene todavía muchos puntos de fricción, en los que a veces entran en abierto enfrentamiento la solución que propone por una parte, la normativa, y la que propone la otra, la empírica, no siendo raro que a veces ésta sea una de las causas de la propia disfunción e ineficacia de las normas jurídico-penales en la solución de determinados conflictos, o que el propio saber empírico carezca de influencia en la regulación jurídica de un determinado problema $\rangle^{111}$. Esta complicada relación se produce en aquellos países donde la Criminología no se halla asentada en tanto, como es el caso de España, se considera una ciencia en nacimiento, carente de estudios rigurosos - dificultosos en cuanto a su elaboración por los constantes obstáculos procedentes desde diversos sectores aunque cada vez más frecuentes en nuestro en país- por lo que o bien no existen semejantes estudios o bien no cuentan con la fuerza suficiente en el ámbito normativo para ser tenidos en consideración. Semejante cuestión no es extrapolable a los países en donde la Criminología goza de un reconocido prestigio social, caso por ejemplo de Estados Unidos, donde, como analizaré en el epígrafe dedicado a los modelos criminológicos imperantes, se fundamenta en un claro utilitarismo social; esto es, la Criminología al servicio de la sociedad siendo bastante frecuentes los estudios llevados a cabo sobre cualquier materia con la única finalidad de proporcionar una información válida para combatir el fenómeno criminal.

\footnotetext{
${ }^{110}$ Por fuentes oficiales cabe entender aquéllas cuyos datos provienen de un organismo público principal. A tal efecto, suelen señalar como ejemplos, las derivadas del Ministerio del Interior, fuente ésta más usada en materia de violencia doméstica; Guardia Civil/Policía Nacional; Ministerio de Justicia; Fiscalía General del Estado, etc. Estos datos son objetivos aunque parciales en su alcance, en tanto van a estar fundamentados en criterios preestablecidos que responden a concepciones jurídicas comprobables mediante algún tipo de documento público, tal y como pueden ser, por ejemplo, las sentencias judiciales, el número de denuncias interpuestas en relación a esta materia, los certificados médico-forenses, etc. Las no oficiales, por el contrario, son aquellas cuya información proviene de otro tipo de documentos indirectos los cuales hacen que, en determinadas ocasiones, se sesgue la realidad. Suelen ser menos fiables que las anteriores en tanto no cuentan con un respaldo propio. Sobre esta cuestión y su plasmación práctica, puede consultarse Morillas Fernández, D. L., Análisis... cit., en prensa.

${ }^{111}$ Hassemer, W. y Muñoz Conde, F., Introducción... cit., p. 24.
} 
En consecuencia, la función de la Criminología en los países pertenecientes al denominado modelo europeo en general, y España en particular, debe modificarse en aras de lograr una correcta relación entre lo que, desde hace tiempo, ha venido en denominarse el "tridente en la lucha contra el crimen"; esto es, una correcta colaboración entre Criminología, Derecho Penal y Política-Criminal, en el sentido de que la Criminología se configure como ciencia independiente permitiendo al Derecho Penal legislar con estudios empíricos reales -críticos o no con la normativa vigente- sobre los que se realicen propuestas de Política-Criminal tendentes a prevenir y actuar contra el delito. Estos parámetros son los que deben regir las relaciones entre Derecho Penal y Criminología en tanto, como manifiestan, Jescheck y Weigend, «la cooperación del penalista con el criminólogo es imprescindible, pues la Criminología suministra a aquél los conocimientos extraídos de la realidad que pueden ser necesarios para la legislación y, de esta forma, las proposiciones jurídicas que pueden ser "materialmente correctas". Le da consejos prácticos para el quehacer diario de la Administración de Justicia penal y, en especial, ofrece al juicio de pronóstico criminal un importante medio de ayuda para reconocer el riesgo de reincidencia, para evitar efectos indeseables de la privación de libertad, para configurar eficazmente la asistencia en la suspensión condicional de la pena (...)»»112. Morillas Cueva se manifiesta en parámetros semejantes al afirmar que «la Ciencia del Derecho penal y la Criminología se presentan como brazos fuertes y vigorosos que conjuntamente han de trabajar para buscar soluciones y para ofrecer un conocimiento claro de la realidad jurídico-penal como parte esencial de la estabilidad del sistema democrático» ${ }^{113}$.

\section{Modelos criminológicos imperantes}

La evolución de la Criminología no ha seguido unas pautas generales o comunes en los distintos países. Por esta razón no es de extrañar las diferencias sustanciales existentes entre las diversas formas de estudiar el crimen, por ejemplo, entre España, donde en la actualidad impera un modelo eminentemente teórico, y Estados Unidos, donde se constituye como una ciencia autónoma enfocada al utilitarismo social. Esta progresión ha dado lugar consecuentemente ha diversos modelos criminológicos dispersos a lo largo de la geografía mundial, los cuales suelen responder al grado evolutivo de esta ciencia.

Como quiera que esta cuestión no es tratada excesivamente en la doctrina criminológica, reseñaré a continuación los tres modelos que, en mi opinión, cohabitan hoy día.

\footnotetext{
${ }^{112}$ Jescheck, H. y Weigend, T., Tratado... cit., p. 51.

${ }^{113}$ Morillas Cueva, L., Curso de Derecho Penal Español. Parte General, Madrid, 1996, p. 70.
} 
3.1. Modelo anglosajón. Sus máximos exponentes se hallan al efecto en Estados Unidos e Inglaterra. Este arquetipo se halla plenamente identificado con las ciencias sociales en tanto parte de la concepción de que la Criminología es un instrumento orientado a la mejora de la sociedad, de ahí su identificación con el utilitarismo social. Su pronta evolución y consolidación la explica García-Pablos al señalar que «se establece entre las ciencias sociales y sociológicas, con clara independencia de las disciplinas jurídicas, desde un principio, logrando un reconocimiento y estabilidad institucional en todos los ámbitos del que careció en Europa» ${ }^{114}$. Representa el grado máximo evolutivo de esta ciencia hasta nuestros días dotando a la Criminología de un papel básico en referencia a los problemas sociales y cumplimentando en su totalidad las funciones anteriormente reseñadas.

3.2. Modelo europeo. La Criminología es una ciencia empírica vinculada al mundo del Derecho residiendo su función principal en la descripción causal del crimen. A diferencia del anterior patrón se trata de un saber eminentemente teórico presente en la mayor parte del continente europeo, con algunas excepciones como es el caso de Inglaterra, y caracterizada por su falta de consolidación ${ }^{115}$. Representaría el polo opuesto al primero.

3.3. Modelo sudamericano. Englobaría un tipo intermedio entre el anglosajón y el europeo no caracterizado como un patrón propio sino más bien como el paso evolutivo intermitente entre ambos. Se caracteriza por presentar una gran variedad de estudios empíricos sobre la totalidad de las figuras objeto de estudio de la Criminología si bien no alcanza a completar el catálogo de funciones; es decir, reúne la base -los estudios criminológicos- pero carece de aplicación. Comprende países como Argentina y México.

Por último, García-Pablos menciona un cuarto patrón, excluible desde mi punto de vista por hallarse hoy día en desuso, si bien es cierto que alcanzó cotas importantes en el pasado y originó diversas teorías criminológicas. Me estoy refiriendo al modelo socialista, fuertemente influenciado por las ideas marxistas y leninis$\operatorname{tas}^{116}$. Este autor destaca «su función "instrumental" al servicio de una ambiciosa y arrolladora "política criminal" consolidadora y guardián del sistema. La Criminología se presenta, entonces, como "ciencia aplicada" en apoyo inmediato

\footnotetext{
${ }^{114}$ García-Pablos de Molina, A., Criminología... cit., p. 151.

${ }^{115}$ Hoy día en España existe un fuerte movimiento social y doctrinal tendente a la consolidación de la Criminología como ciencia propia. El aumento de estudios criminológicos por parte de los Institutos de Investigación-verbigracia el Instituto Andaluz Interuniversitario de Málaga o el propio Departamento de Derecho Penal de la Universidad de Granada con sendas iniciativas en materia de violencia doméstica y drogas- desvelan una creciente preocupación por la realización de este tipo de trabajos empíricos que puedan dotar de consistencia jurídica diversos aspectos regulados en el Código Penal. Asimismo la creación de una nueva Licenciatura en Criminología plantea un horizonte de expectativas positivas en relación con el re-descubrimiento de la Criminología.

${ }^{116}$ García-Pablos de Molina, A., Criminología ... cit., p. 150.
} 
de la realidad práctica y de la legalidad socialista» ${ }^{117}$. Entre sus características principales suele reseñarse una primacía radical a la infraestructura económica como factor determinante de cualquier cambio o fenómeno social, la utopía de la erradicación total del crimen o su caracterización como mero instrumento o disciplina auxiliar de la Jurisprudencia ${ }^{118}$. En mi opinión, más que un modelo criminológico, este pensamiento refleja una serie de teorías dotadas de contenido en el seno del paradigma del conflicto o control social.

\section{BIBLIOGRAFÍA}

- BECKER, G., «Crime and Punishment: An Economic Approach», en Journal of Political Economy,76, 1968.

- BERNALdO DE QUIRÓS, C., Criminología, Puebla, 1957.

- BUSTOS RAMÍREZ, J. y Larrauri Pijoan, E., Victimología: Presente y Futuro, Barcelona, 1993.

- CLARKE, D. Y CORNISH, D., «Modeling Offenders' Decisions: A Framework for Research and Policy», en Tonry y Morris, Crime and Justice. An Annual Review of Research, vol. 6, Chicago, 1985.

- ClOWARD, R. Y OHLIN, L., Delinquency and opportunity. A theory of delinquent gangs, Nueva York, 1960.

- COHEN, A. Y FELSON, M., «Social change and crime rate trends: a routine activity approach», en Annual Review of Sociology, 44, 1979.

- COHEN, A., DELINQUENT BOYS. The Culture of the Gang, 1955, Illinois.

- COHEN, S. «Visiones de control social», Traducido al castellano por E. Larrauri, 1988.

- CONKLIN, J., Criminology, 1995.

- CUBÍ Y SOLER, M., Manual de frenología, Barcelona, 1843.

- DELlA PORTA, De humana physiognomia, Sorrent, 1586.

- DURKHEIM, E., El suicidio. Estudio de Sociología, Madrid, 1928.

- DURKHEIM, E., Las reglas del método sociológico, Madrid, 1991.

- GARCÍA-PABLOS DE MOLINA, A., Criminología: una introducción a sus fundamentos teóricos, Valencia, 2001, p. 33.

- GARCÍA-PABLOS DE MOLINA, A., Tratado de Criminología, Valencia, 1999.

- GARFINKEL, H., «Conditions of Successful Degradation Ceremonies», en Symbolic Interacionism, Nueva York, 1972.

\footnotetext{
${ }^{117}$ García-Pablos de Molina, A., Tratado... cit., pp. 68 y 69.

${ }^{118}$ García-Pablos de Molina, A., Criminología... cit., p. 357.
} 
- GARRIDO, V., STANGELAND, P. Y REDONDO, S., Principios de Criminología, Valencia, 2001.

- GLUECK, S. Y E., PHYSIQUE AND DELINCUENCY, NEW YORK, 1956.

- GÖPPINGER, H., Criminología, Madrid, 1975.

- GUlOTTA, G., La vittima, Italia, 1976.

- HASSEMER, W. Y MUÑOZ CONDE, F., Introducción a la Criminología, Valencia, 2001.

- $\quad$ HENTIG, H., El delito, Madrid, 1975.

- Hentig, H., The Criminal and his Victim, New Haven, USA, 1948.

- Herrero herrero, C., Criminología, Madrid, 2001.

- HIRSCHI, T. Y STARK, R., «Hellfire and delinquency», en Social Problems, 17, 1969.

- JAMBU-MERLIN, R., STEFANI, G. Y LEVASSEUR, G., Criminologie et Science pénitentiaire, París, 1985.

- JESCHECK, H. Y WEIGEND, T., Tratado de Derecho Penal, Traducción de Miguel Olmedo Cardenete, Granada, 2002.

- KAISER, G., Criminología. Una introducción a sus fundamentos científicos, Madrid, 1983.

- KAISER, G., Introducción a la Criminología, Madrid, 1988.

- KRETSCHMER, Köperbau und Charakter, Berlín, 1921.

- LATORRE, A., Introducción al Derecho, Barcelona, 1969.

- LEMERT, E., Devianza, problemi sociali e formi di controllo, Milán, 1981.

- LOMBROSO, L'uomo delincuente, $1^{a}$ Edición, Milán, 1876.

- MANHEIM, H., Comparative Criminology, Londres, 1965.

- MANTOVANI, F., Il problema della criminalità, Milán, 1984.

- MATZA, D., Delinquency and Drift, Nueva York, 1964.

- MENDELSOHN, B., «La Victimologie», en Revue Francais de Psychenalise, janvierfevrier, 1958.

- MORILlaS CUEVA, L., Curso de Derecho Penal Español. Parte General, Madrid, 1996.

- MORILlas CUEVA, L., Metodología y Ciencia Penal, Granada, 1993.

- MORILlaS FERNÁNDEZ, D. L., Análisis criminológico del delito de violencia doméstica, Cádiz, 2003

- MORILLAS FERNÁNDEZ, D. L., «Aspectos criminológicos de los psicópatas y asesinos en serie», en Cuadernos de Política Criminal, nº 77, 2002.

- MORILLAS FERNÁNDEZ, D. L., «Malos tratos a personas mayores: otra forma de violencia», en Actas de las Primeras Jornadas de Problemas Legales sobre Tutela, Asistencia y Protección a las Personas Mayores, Córdoba, 2001; o su versión electrónica en 
Revista Electrónica de Ciencia Penal y Criminología, núm 2, 2000 (http://criminet.ugr. es/recpc/recpc_02-r4.html).

- MORILLAS FERNÁNDEZ, D. L., «Notas criminológicas sobre el consumo de drogas», en Morillas Cueva, Estudios jurídico-penales y político-criminales sobre tráfico de drogas y figuras afines, Madrid, 2003.

- MORILLAS FERNÁNDEZ, D. L., «Víctimas especialmente vulnerables en el delito de violencia doméstica», en Morillas Cueva, Estudios penales sobre violencia doméstica, Madrid, 2002.

- POPPER, K. Conjeturas y refutaciones. El desarrollo del conocimiento científico, Barcelona, 1989.

- POPPER, K., The Poverty of Historicism, Londres, 1976.

- RAINE, A., The psychopathology of crime: criminal behaviour as a clinical disorder, San Diego, 1993.

- REAL ACADEMIA ESPAÑOLA, Diccionario de la Lengua Española, 2001, versión electrónica (http://www.rae.es)

- RODRÍGUEZ MANZANERA, L., Criminología, México, 1982.

- RODRÍGUEZ MANZANERA, L., Victimología, México, 1990.

- SAINZ CANTERO, J. A., Lecciones de Derecho Penal, vol. I, Barcelona, 1979.

- SCHNEIDER,H., Kriminologie, Nueva York, 1987.

- SERRANO GÓMEZ, A. Y SERRANO MAÍlLO, A., «La paradoja del descubrimiento de la Criminología en España», en La ciencia del Derecho Penal ante el nuevo siglo, Libro Homenaje al Prof. Dr. D. José Cerezo Mir, Madrid, 2002.

- SERRANO GÓMEZ, A., Introducción a la ciencia del derecho penal, Madrid, 1981.

- SERRANO MAÍLLO, A., Introducción a la Criminología, Madrid, 2003.

- SHELDON, Varieties of Delincuent Youth, Harper, 1949.

- SIEGEL, L., Criminology, Belmont, 2002.

- SUÁREZ LÓPEZ, J. M., El concurso real de delitos, Madrid, 2001.

- SUTHERLAND, E., «White Collar Criminality», en American Sociological Review, 5, 1940.

- VEGA RUIZ DE, J. A., Las agresiones familiares en la violencia doméstica, Pamplona, 1999.

- WILSON, J. Y HERRNSTEIN, R., Crime and Human Nature. The definitive study on the causes of crime, Nueva York, 1985

- WOLF, K.H. «Soziale Kontrolle», en Wörterbuch der Soziologie, editado por Bernsdorf, W., 1969.

- ZAFIROVSKI, M., «The rational choice generalization of neoclassical economics reconsidered: any theoretical legitimation for economic imperialism?», en Sociological Theory, 18, 2000. 
